\title{
A geometria oculta das calçadas de Paris
}

\author{
The hidden geometry on Parisian sidewallks
}

\author{
Airton Cattani \\ Arquiteto, Professor Titular \\ do Curso de Design e do \\ Programa de Pós-Graduação \\ em Design da UFRGS, Porto \\ Alegre, Brasil. \\ aacc@ufrgs.br \\ ORCID: \\ http://orcid.org/0000-0001- \\ 8081-7704
}

\section{RESUMO:}

Embora nem sempre percebida, a geometria está presente em todos os aspectos de nosso cotidiano, manifestando-se ora explicitamente, ora de maneira mais discreta, de modo que tenhamos que fazer um esforço para percebê-la. Procurando mostrar que sempre há algo onde aparentemente não há nada, este relato apresenta os resultados de uma pesquisa visual sobre as calçadas de Paris, salientando sua geometria casual, provavelmente pouco percebida pelos pedestres. Os resultados mostram que, apesar de sua aparentemente falta de expressividade, as calçadas da cidade "escondem" uma geometria própria e espontânea, fruto de intervenções feitas por anônimos operários que, involuntariamente, deixam suas marcas sobre os pavimentos, conferindo-lhes um aspecto peculiar sob o ponto de vista da geometria. A pesquisa dá seguimento às investigações que o autor vem desenvolvendo desde 2005 sobre o tema calçadas urbanas.

Palavras-chave: calçadas, pavimentos, design de superfície, Paris.

\section{ABSTRACT:}

Despite not being perceived, geometry is present in our daily lives, in a explicitly or more discreetly way, so we must strive to perceive it. Seeking to show that there is always something where there apparently is nothing, this article presents the results of a visual survey on the sidewalks of Paris, highlighting its casual geometry, probably not noticed by pedestrians. Despite the apparent lack of expressiveness, the results show that the Parisian sidewalks "hide" a kind of spontaneous geometry, resulting from interventions by anonymous workers who, involuntarily, leave their marks on the city sidewalks, giving them a peculiar aspect in a geometric point of view. The research follows the approach that has been developed by the author since 2005 on the theme of urban sidewalk.

Keywords: sidewalks, pavements, surface design, Paris. 


\section{INTRODUÇÃO}

Equipamento urbano essencial, nem sempre as calçadas cumprem outras funções além daquela originalmente prevista, qual seja, ser uma superfície para o deslocamento preferencial de pedestres e eventuais bicicletas, patins, carrinhos de bebê e outros meios de transporte leves. Tendo em conta estes requisitos de ordem funcional, a escolha dos revestimentos para calçadas costuma levar administradores e gestores urbanos a optarem, via de regra, por aqueles que terão melhor custo/benefício/desempenho, deixando questões estéticas em um plano secundário, fazendo com que prevaleça o atendimento a questões de ordem técnica. Isso faz com que sejam poucas as cidades que tenham calçadas que se destacam sob o ponto de vista visual. Assim, não são numerosas as cidades onde este elemento do mobiliário urbano é valorizado como patrimônio, podendo ser citadas Rio de Janeiro ou Lisboa, com suas maravilhosas calçadas de pedras portuguesas, documentadas, entre outros, por Teixeira e Veiga (2007) e Matos (2011) respectivamente. Ou mesmo Porto Alegre, com sua grande diversidade de matérias, texturas e cores presentes em suas calçadas que, no entanto, requererem por parte dos pedestres ou pesquisadores um certo esforço para serem reconhecidas como portadoras de atributos estéticos (Cattani; Pesavento; Trevisan, 2007).

Desde 2005 o autor deste artigo vem desenvolvendo pesquisas em que procura documentar fotograficamente aspectos estéticos de calçadas de várias cidades. Afastando-se das estruturas normativas de pesquisas em design ou arquitetura, que costumam contemplar tópicos como metodologia, problema de pesquisa, hipóteses e outros requisitos de ordem técnico/acadêmica em abordagens mensuráveis quantitativamente ou passíveis de hierarquização, a busca por resultados nesta pesquisa obedeceu a critérios de conveniência e interesse pessoal, registrando fotograficamente as peculiaridades das calçadas, de modo destacar seus aspectos plástico/visuais com destaque para a geometria espontânea. Os registros têm sido feitos por ocasião de visitas a diversas cidades, sempre com um olhar direcionado à procura de aspectos pouco percebidos por pedestres ou turistas. Esta temática já foi motivo de diversas publicações (Cattani; Pesavento; Trevisan, 2007; Cattani; Vieira; Ying, 2019; Cattani, 2021), onde calçadas de cidades como Porto Alegre e Beijing foram documentadas. Neste relato são apresentados os resultados de pesquisa visual realizada por ocasião de estágio pós-doutoral em Paris, em 2016, que resultou em outra publicação (Cattani; Leenhardt, 2021).

Uma das cidades mais visitadas do mundo, recebendo milhões de turistas todo o ano, Paris tem um ambiente urbano notável que, no entanto, não se caracteriza por alguma peculiaridade de suas calçadas além de seu caráter utilitário. Quase todas revestidas com asfalto, as calçadas da cidade têm superfícies homogêneas e regulares, aparentemente desprovidas de atributos estéticos que façam turistas ou pesquisadores se interessar por elas. No entanto, quando observadas por um olhar atento e curioso, quase em um 
passe de mágica elas passam a apresentar detalhes que as tornam únicas. Este relato apresenta alguns resultados dessa pesquisa, onde a geometria "oculta" das calçadas de Paris é posta em evidência, provando que sempre há algo para ser visto, mesmo onde, aparentemente, não haja nada.

\section{0 QUE VER ONDE NINGUÉM VÊ NADA}

A quantidade de fotografias tomadas diariamente em Paris talvez possa ser contada aos milhões. Assim como em várias outras cidades turísticas, não existe um lugar, um recanto, um detalhe da cidade que não tenha sido registrado por lentes fotográficas de todas as espécies: monumentos, ruas, praças, portas, janelas, pessoas, pontes, praticamente tudo que é fixo ou se move é incessantemente fotografado por profissionais ou amadores, o que certamente faz de Paris uma das cidades mais fotografadas do mundo. E os olhares destes fotógrafos são os mais diversos, assim como os seus equipamentos fotográficos: desde o olhar distraído e mais preocupado com a quantidade de fotos tomadas do turista amador, até o olhar atento e obstinado pela perfeição técnica e formal do fotógrafo profissional, nada escapa ao registro fotográfico que quer capturar alguma coisa da magia desta cidade. Mesmo quando um novo monumento, um local ou uma intervenção artística passam a fazer parte da paisagem da cidade, imediatamente tornam-se objeto de milhões de fotografias. Assim, aparentemente, a cidade não ofereceria nenhuma novidade em termos de temática fotográfica, condenando os fotógrafos a se debruçarem sempre sobre os mesmos lugares e coisas, fotografando-os à exaustão. Mas Paris é surpreendente, e mesmo assediada diariamente pela fúria das lentes fotográficas de toda a espécie, consegue reservar algumas surpresas que se oferecem ao olhar atento, disposto a ver algo onde ninguém vê nada. Muitas vezes, essas surpresas estão debaixo de nossos pés...

As calçadas de Paris se caracterizam por uma relativa pobreza cromática e formal, principalmente se comparadas com cidades onde este elemento do mobiliário urbano é valorizado como parte importante do patrimônio edificado. Exceto em algumas áreas onde as calçadas são projetadas com mais cuidado - mas sempre com sobriedade, sem exageros formais ou cromáticos -, na maior parte das calçadas da cidade é empregado o asfalto como material de revestimento (Figura 1). 
Figura 1 - Aspectos de calçadas de Paris, revestidas com asfalto e aparentemente sem atributos estéticos relevantes.
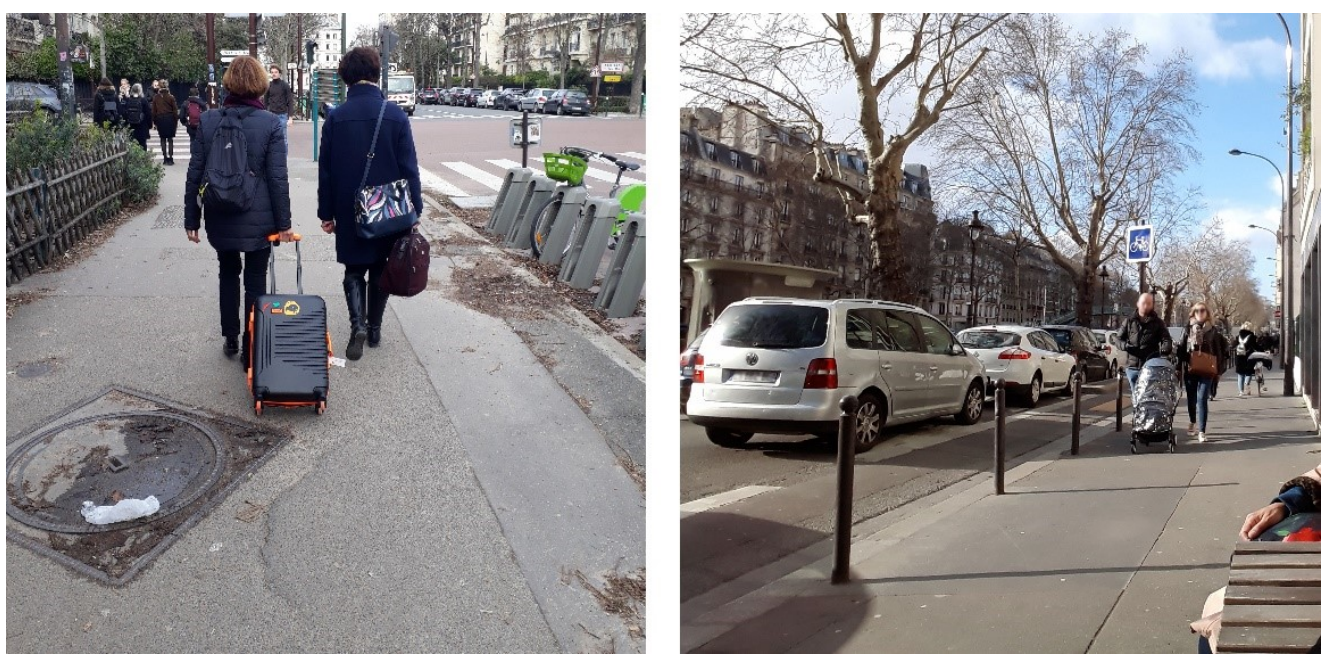

Fonte: acervo do autor (2016).

Se por um lado este material apresenta grande durabilidade, resistência e facilidade de reposição, além de proporcionar superfícies regulares para o trânsito de pedestres, carrinhos de bebês, cadeiras de rodas e equipamentos de carga e descarga, por outro lado revela-se extremamente monótono do ponto de vista visual, constituindo-se em uma superfície homogênea e praticamente monocromática, aparentemente sem qualquer outro atributo. No entanto, observando melhor consegue-se perceber que, mesmo onde aparentemente existem mínimas possibilidades de encontrar algo relevante do ponto de vista visual, há algo que pode apresentar algum atributo estético.

Cotidianamente as calçadas parisienses são escavadas para serviços de manutenção/reparação de equipamentos ou serviços subterrâneos, como água, luz, esgoto e instalações em geral. Após os serviços serem executados, o asfalto é imediatamente recuperado, restituindo-se a homogeneidade às calçadas, só restando como vestígios dessas intervenções as linhas de delimitação entre o asfalto original e o novo. Se é possível recuperar a homogeneidade e regularidade das superfícies, isso não ocorre em relação ao aspecto cromático, pois nem sempre é possível obter a mesma tonalidade na cor do asfalto; conforme os materiais utilizados na sua composição, o asfalto apresenta uma variedade de tons de cinza, indo dos mais claros aos quase pretos. Como resultado, as calçadas parisienses ostentam em suas superfícies uma diversidade de formas geométricas e matizes (mono)cromáticos resultantes de intervenções feitas por anônimos operários (Figura 2). 
Figura 2 - Diferentes tipos de asfalto empregado na recuperação de calçadas. Avenue du General Lecrerc.

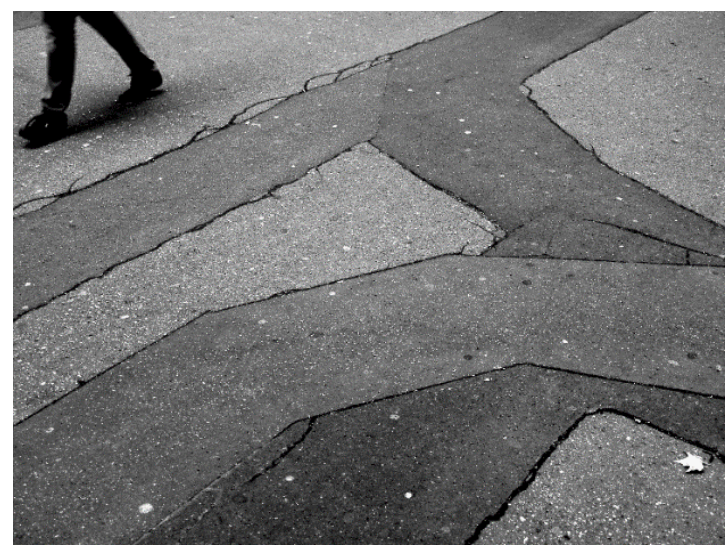

Fonte: acervo do autor (2016).

Originadas de requisitos pragmáticos - escava-se apenas em uma área necessária à intervenção -, as formas resultantes da recomposição do pavimento são casuais, aparentemente sem nenhuma outra lógica além do pragmatismo, mas que acabam criando uma geometria muito particular, as vezes mais explícita, outras vezes mais sutil, ao ponto de desaparecer nos dias de chuva, quando a água torna as superfícies cromaticamente homogêneas. A própria natureza também parece oferecer sua contribuição para a personalização das calçadas da cidade, participando dessa estranha geometria aleatória: recalques no terreno fazem com que o asfalto se acomode, fazendo surgir linhas parecidas com rachaduras, mas que não oferecem nenhum perigo, talvez algum prazer estético (Figura 3).

Figura 3 - Fissuras na superfície de calçada, originada do recalque do terreno. Avenue Paul Daumer.

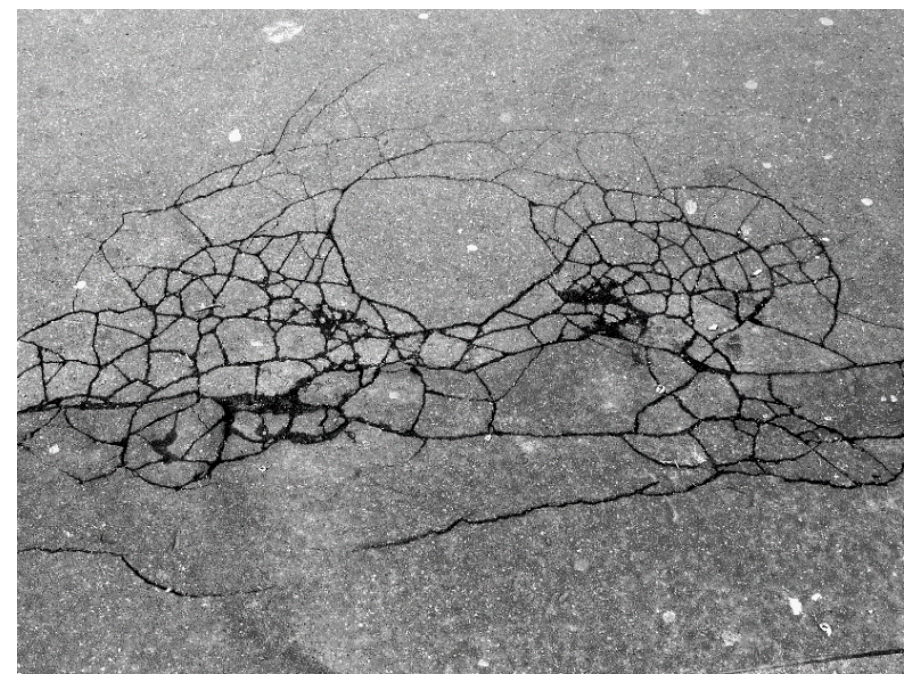

Fonte: acervo do autor (2016).

Os próprios pedestres também contribuem involuntariamente para uma estética própria das calçadas: cuspindo suas gomas de mascar, fazem com 
que trechos do pavimento pareçam mostrar vestígios da passagem de Yayoi Kusama (Figura 4).

Figura 4 - Gomas de mascar na superfície de uma calçada. Avenue de la République.

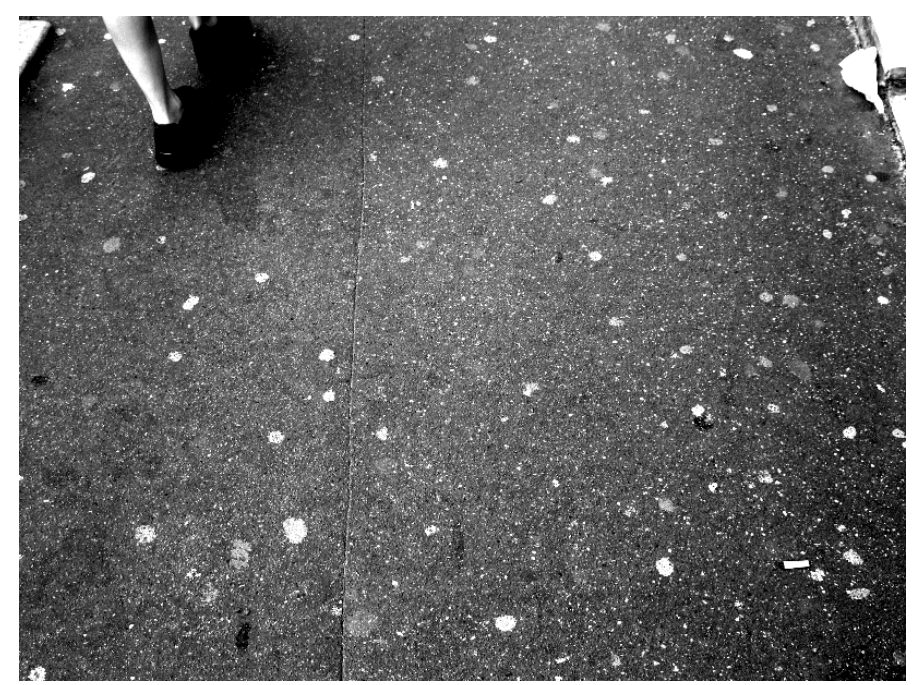

Fonte: acervo do autor (2016).

Em oposição ao aspecto figurativo e inteligível característico da cidade, com seus belos edifícios haussmanianos, seus espaços naturais, seus eixos monumentais e suas perspectivas magníficas, as calçadas mostram uma face geometricamente abstrata de Paris, provando que a geometria e o abstracionismo não estão somente nas escolas ou nas paredes das galerias e museus da cidade; basta ir para a rua e olhar para baixo, em qualquer lugar, em qualquer esquina. Como se tivessem autonomia em relação à sua aparência, as calçadas parecem imitar Mondrian, Kandinsky, van Doesburg, de Kooning, Rothko e outros artistas abstratos, querendo nos mostrar que a arte nesta cidade está por todo lugar, até na geometria peculiar e casual de suas calçadas; é só olhar para elas e nos deixar sensibilizar (Figura 5). 
Figura 5 - Composição geométrica aleatória na calçada do Boulevard Raspail.

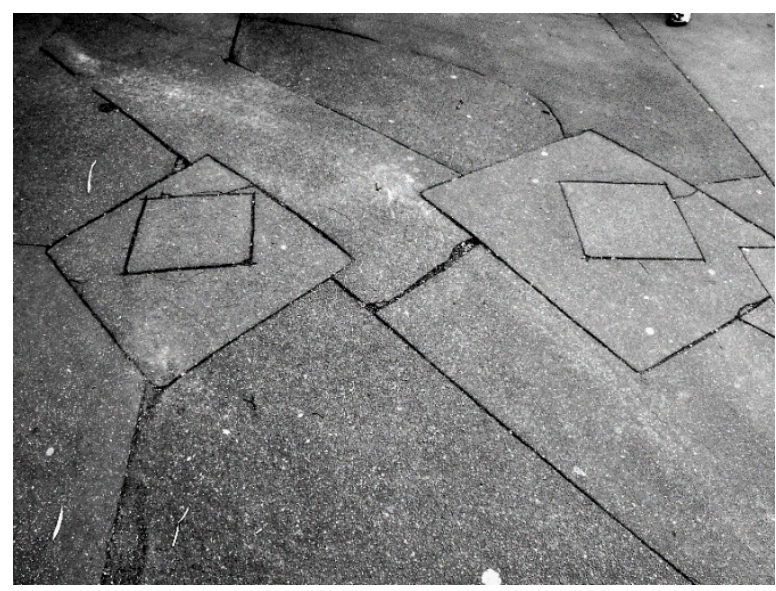

Fonte: acervo do autor (2016).

São essas circunstâncias fortuitas que acabam por conferir às calçadas uma certa originalidade, mesmo caracterizadas pelo uso do mesmo material e pela homogeneidade cromática. Assim, linhas de todos os tipos, ângulos nos mais variados gradientes, polígonos de todas as formas e inúmeras outras superfícies geométricas em matizes que vão do cinza ao preto apresentam-se aos pés de quem passa pelas calçadas de Paris. Apesar de estarem à mostra para todos, provavelmente poucos as percebem. Seu testemunho da participação da vida da cidade passa despercebidamente, pois sua presença se resume apenas à linhas e superfícies anônimas, inúmeras vezes pisoteadas. No entanto, são marcas existentes que documentam um aspecto da história da cidade, embora não sejam tão vigorosas ou imponentes como uma torre, uma ponte, uma catedral. Simplesmente estão lá, cada uma a seu modo, deixando as marcas de seu passado de pouca relevância - mas significativo, pois existiu - resistindo ao esquecimento e se oferecendo para leituras de quem quiser lêlas e interpretá-las, seja lá de que forma for (Figura 6). 
Figura 6 - Formas geométricas aleatórias na calçada da Avenue Daumesnil.

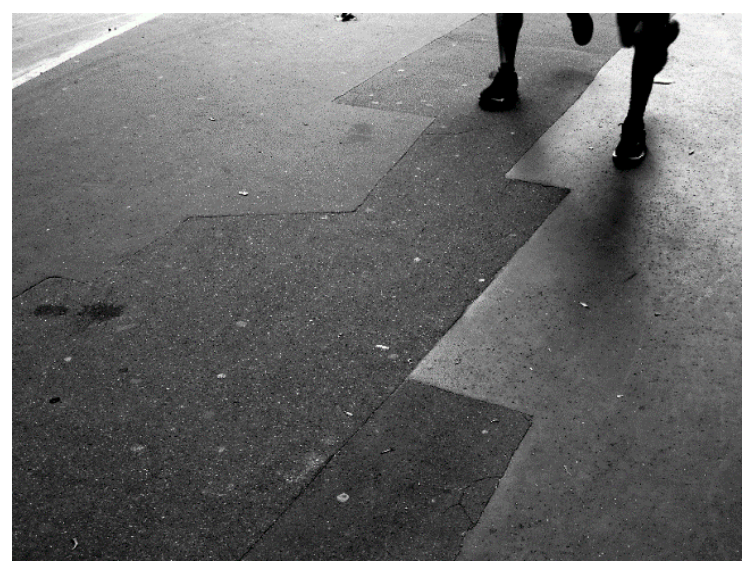

Fonte: acervo do autor (2016).

A constatação empírica da existência de uma riqueza visual nas calçadas da cidade, praticamente desconsiderada por acadêmicos ou pesquisadores ou mesmo por seus habitantes, fez com que fosse iniciada uma coleta sistemática de fotografias de detalhes encontrados nessas superfícies. Assim, centenas de fotografias foram tomadas em promenades au hasard durante a primavera de 2016, sempre olhando para baixo - o que não é muito fácil em uma cidade que tem tantas coisas magníficas para se ver - à procura das sutilezas que as mudanças do asfalto produzem sobre as calçadas. Como método de coleta foi estabelecido que as fotografias deveriam abranger apenas as superfícies horizontais, sem mostrar edificações e sem ter um caráter turístico. Como extensão geográfica, procurou-se incluir calçadas de todos os treze arrondissements de Paris. Todas as fotografias foram tomadas em orientação paisagem, com um equipamento Olympus E500 com lente $30 \mathrm{~mm}$, sendo denominadas com o nome da rua onde a calçada estava localizada. Após, as fotos foram tratadas no software Photoshop, convertidas para tons de cinza e, na sequência, corrigido o balanço de brancos e ajustado o contraste.

\section{O LIVRO}

A análise de centenas de fotografias tomadas permitiu constatar seu potencial para uma publicação. Deste modo, foi idealizado o livro Uma cidade abstrata a seus pés = Une ville abstraite sous vos pieds (Cattani; Lennhardt, 2021) em edição bilíngue (português e francês) onde as fotografias são acompanhadas de textos do autor e um prefácio de Jacques Leenhardt, filósofo e sociólogo, diretor de estudos da École des Hautes Études en Sciences Sociales - EHESS, em Paris. As dimensões do livro são $210 \times 210 \mathrm{~mm}$, com margens superiores e laterais de $25 \mathrm{~mm}$ e margem inferior de 6,5 mm (Figura 7). 
Figura 7 - Capa do livro Uma cidade abstrata a seus pés = Une ville abstraite sous vos pieds .

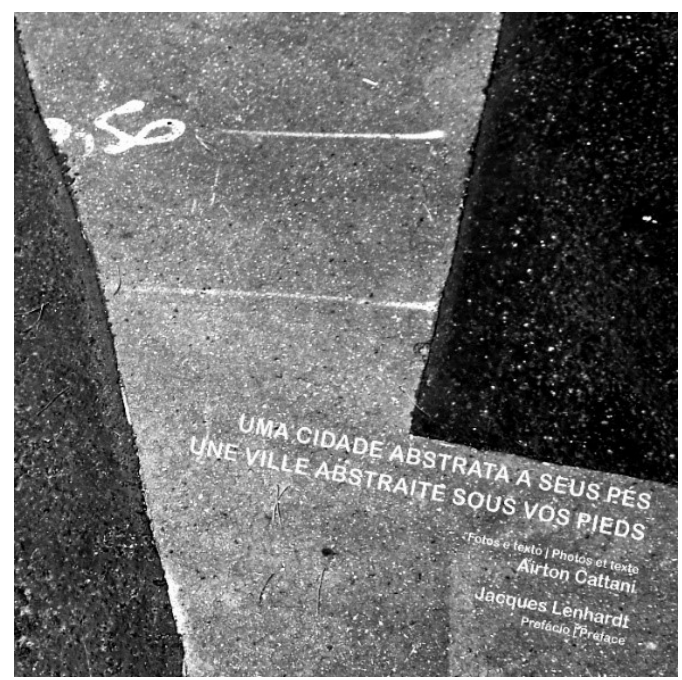

Fonte: acervo do autor (2021).

A diagramação dos textos e imagens contempla três situações básicas:

1) Páginas com textos e fotos; nesta situação as fotos são inseridas na página da direita, de modo a privilegiá-las, pois são o primeiro elemento gráfico percebido pelo leitor. Caixa de texto e imagens têm as mesmas dimensões de $160 \times 120 \mathrm{~mm}$. 0 fato de existir apenas uma fotografia nestas páginas, permitiu exercer uma certa liberdade na escolha das mesmas, optando-se por aquelas onde estivesse registrado aspectos peculiares, como diversos matizes de cinza, formas inusitadas, figuras geométricas aleatórias, contrastes formais e texturas diversas (Figura 8).

Figura 8 - Páginas do livro, apresentando texto e foto lado a lado.

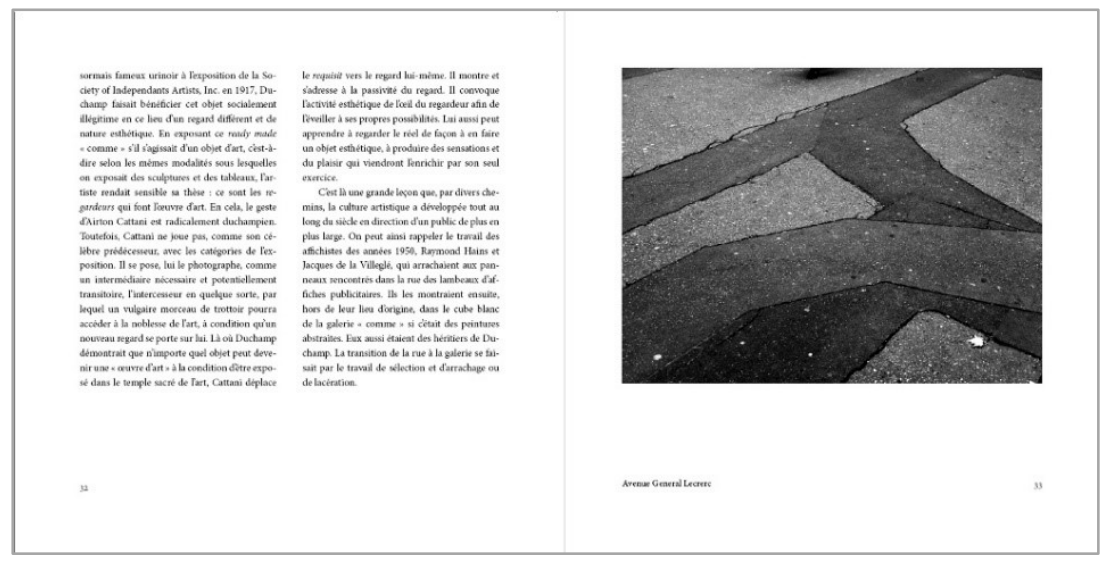

Fonte: acervo do autor (2021).

2) Páginas com fotos em dupla; nesta situação a escolha das fotos não foi aleatória, pois o par de fotos faz uma referência ao trabalho de Aloísio Magalhães (1927-1982), um dos pioneiros do design moderno brasileiro. Na década de 1970, Aloísio criou diversas obras que chamou de cartemas. Utilizando cartões postais como elemento gerador da 
criação, os cartemas são composições gráficas que partem de um elemento comum que é rotacionado e repetido, de modo que a imagem resultante se torne algo diferente da imagem original, mas guardando alguma relação com ela ao mesmo tempo em que cria uma nova experiência visual. (Figura 9).

Figura 9 - Cartema de Aloísio Magalhães da série Cartemas Brasileiros, 1972. Cartões-postais justapostos colados sobre eucatex, $90 \times 60 \mathrm{~cm}$.

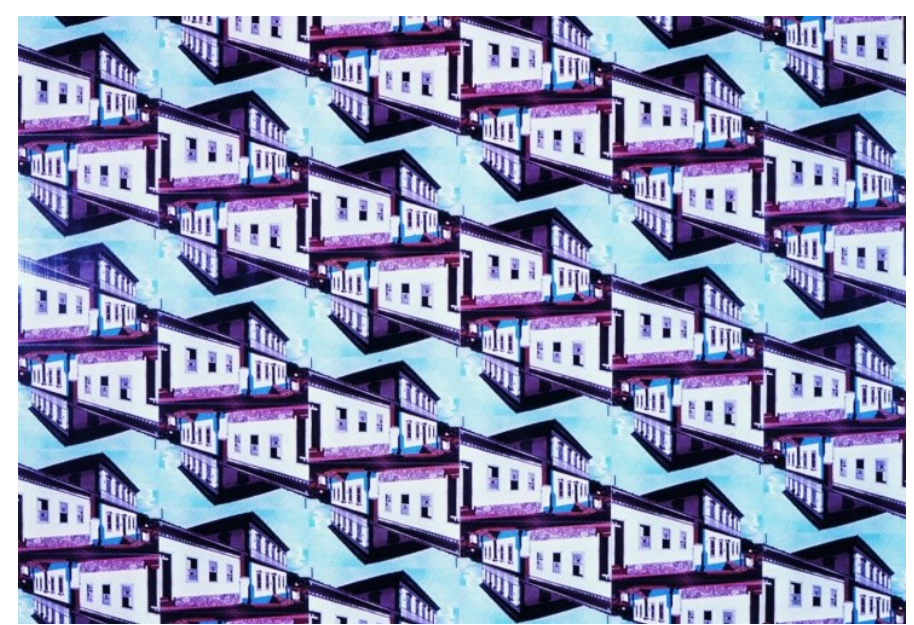

Fonte: https://www.itaucultural.org.br/ocupacao/aloisio-magalhaes/cartemas (2021)

Nas composições das fotos em dupla, os pares de imagens foram cuidadosamente escolhidos, de modo a propiciar uma visualização em que essas fotografias sejam consideradas como duas imagens independentes e, simultaneamente, uma terceira imagem, em que as duas são percebidas como uma unidade visual, acentuada por elementos formais ou cromáticos de continuidade, como linhas, texturas e tons de cinza (Figuras 10 e 11).

Figura 10 - Páginas do livro apresentando fotos em duplas formando uma nova unidade visual.

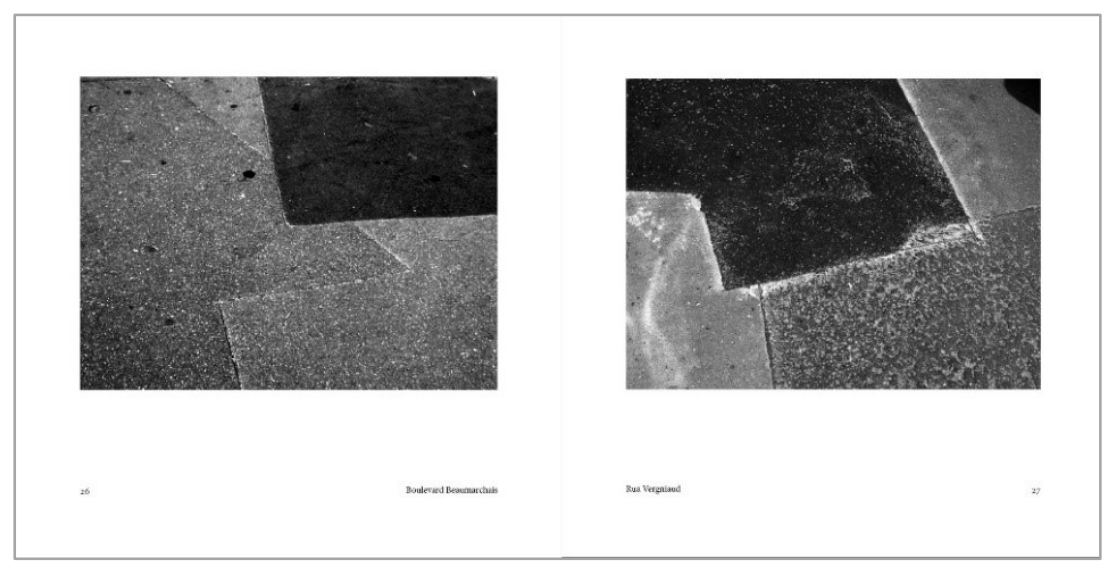

Fonte: acervo do autor (2021). 
Figura 11 - Páginas do livro, apresentando fotos em duplas formando uma nova unidade visual.

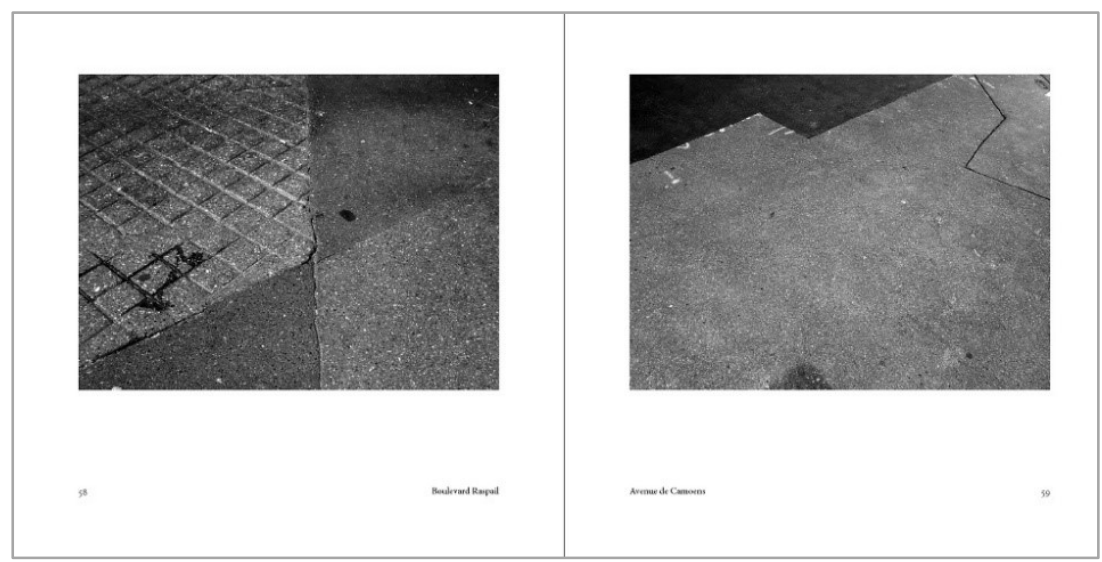

Fonte: acervo do autor (2021).

3) Páginas com fotos em mosaico; assim como foi feito nas páginas duplas, as imagens para compor os mosaicos foram cuidadosamente escolhidas, de modo que pudessem ser observadas como unidades visuais isoladas e independentes, mas ao mesmo tempo pudessem ser vistas simultaneamente como um conjunto com novo significado, novamente fazendo uma referência à obra de Aloísio Magalhães. A escolha procurou fazer com houvesse alguma continuidade entre linhas, formas e tons, de maneira que o conjunto pudesse ser percebido como uma nova imagem (Figura 12).

Figura 12 - Páginas do livro, apresentando fotos em mosaico, formando novos conjuntos visuais.

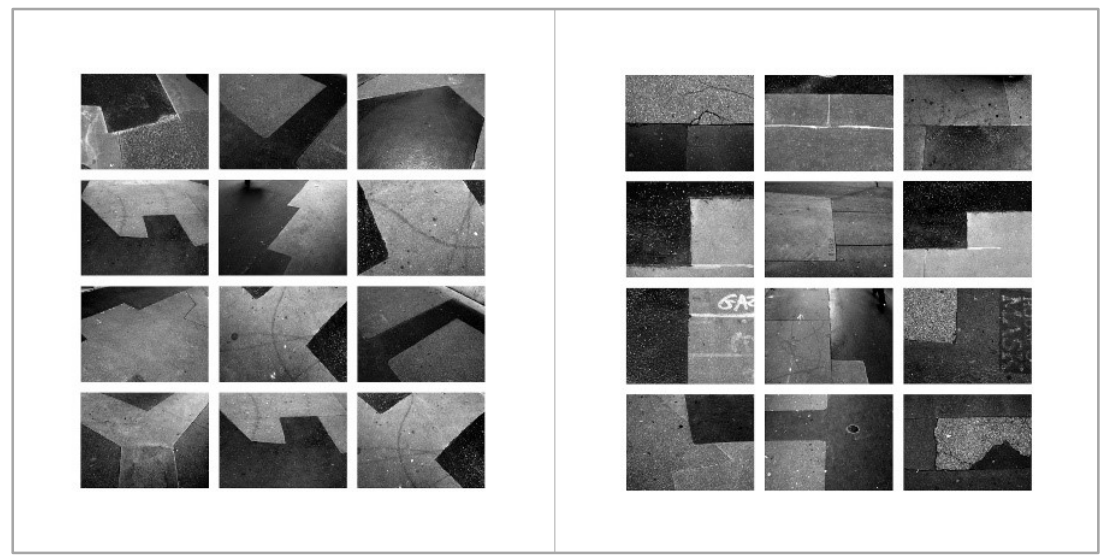

Fonte: acervo do autor (2021).

Assim, este livro se constitui em um duplo exercício: mostrar aspectos da geometria oculta das calçadas de Paris, ao mesmo tempo em que as fotografias apresentadas se constituem em elementos independentes e que fornecem simultaneamente novas abordagens visuais. Embora realistas, pois documentam algo que efetivamente existe e está lá - alguns pés fortuitos provam isso -, as imagens procuram mostrar o caráter abstrato que as calçadas involuntariamente apresentam, abstração que se torna até dramática 
quando acentuada pelo preto e branco das fotografias, ou quando apresentadas em duplas ou em mosaico de várias imagens.

\section{CONSIDERAÇÕES FINAIS}

Mais do que mais um livro sobre Paris, esta obra procura por em evidência um aspecto pouco observado no cotidiano da cidade: a geometria casual "escondida" em suas calçadas. Alguns poderão dizer que as fotografias apresentam apenas formas e linhas. Apenas? E por acaso elas não são belas, quando olhadas com o cuidado e atenção? Não foi Fernando Pessoa que disse que “...as pedras são engraçadas / Quando a gente as tem na mão / E olha devagar para elas."? (Pessoa, 1980, p. 143). Não podemos pegar estas calçadas na mão, somente podemos nos apropriar delas com nosso olhar. E olhando-as devagar poderemos perceber que suas formas podem até ser engraçadas e, de alguma maneira, nos sensibilizar.

Este livro também procura mostrar que uma temática fotográfica nem sempre precisa ser inusitada, exótica ou de difícil acesso, ou ser feita com equipamentos sofisticados para produzir resultados expressivos. Assim, foi o olhar curioso, preocupado em selecionar um fragmento banal da realidade, que agora proporciona ao leitor a possibilidade de ver este fragmento de um modo como nunca havia visto antes, como quem quer dizer: "Veja, você vê isso todos os dias. Mas... já reparou como é belo, como é diferente?". Assim como Georges Perec (2016) tentou esgotar a descrição da praça Saint-Sulpice, descrevendo "o que acontece quando nada acontece", estas fotografias tentam mostrar que há alguma coisa onde - aparentemente - não há coisa nenhuma.

Depois de ver estas fotografias, certamente o leitor nunca mais deixará de observar atentamente as calçadas por onde passa, por mais singelas que possam ser e onde quer que estejam localizadas, à procura de suas peculiaridades. Talvez essa possa ser uma das funções da fotografia: retirar algo de seu contexto e mostrá-lo isoladamente, de modo que possa ser apreciado devagar e proporcionando uma relação sensorial de prazer estético, mesmo quando proveniente de algo tão banal como uma calçada. E para isso não é preciso ir muito longe, basta olhar para baixo. Muitas vezes, o inusitado, o curioso, o peculiar - e, por que não? - o belo, podem estar debaixo de nossos pés....

Uma versão digital do livro está disponível em: https://lume.ufrgs.br/bitstream/handle/10183/220227/001124886.pdf?se quence $=1 \&$ is Allowed $=\mathrm{y}$

\section{REFERÊNCIAS}

CATTANI, Airton; PESAVENTO, Sandra Jatahy; TREVISAN, Armindo. Olhe por onde você anda: calçadas de Porto Alegre. Porto Alegre: Editora da UFRGS, 2007. 
CATTANI, Airton; VIEIRA, César Bastos de Mattos; YING, Lu (Org.). Calçadas de Porto Alegre e Beijing = Sidewalks from Porto Alegre and Beijing = 阿雷格里 港和北京的人行道. Porto Alegre: Marcavisual, 2019. Versão digital disponível em https://lume.ufrgs.br/bitstream/handle/10183/219574/001124198.pdf?se quence=1\&isAllowed=y Acesso em 18/04/2021.

CATTANI, Airton; LEENHARDT, Jacques. Uma cidade abstrata a seus pés = Une ville abstraite sous vos pieds. Porto Alegre: Marcavisual - Faculdade de Arquitetura da UFRGS, 2021. Versão digital disponível em https://lume.ufrgs.br/bitstream/handle/10183/220227/001124886.pdf?se quence=1\&isAllowed=y Acesso em 24/04/2021.

CATTANI, Airton. Olhando para cima e para baixo no Wangjing SOHO = Looking up and down in Wangjing $\mathrm{SOHO}=$ 在扎哈哈迪德项目上向上下寻找. Porto Alegre: Marcavisual - PGDesign, 2021. Versão digital disponível em https://lume.ufrgs.br/bitstream/handle/10183/219311/001124147.pdf?se quence $=1 \&$ isAllowed=y Acesso em 18/04/2021.

MATOS, Ernesto. Calçada portuguesa de Portugal / Portuguese stone pavement of Portugal. Lisboa: Sessenta e Nova Manuscritos, 2011.

PEREC, Georges. Tentativa de esgotamento de um local parisiense. São Paulo; Gustavo Gili, 2016.

PESSOA, Fernando. O eu profundo e os outros eus. Rio de Janeiro: Nova Fronteira, 1980.

TEIXEIRA, Iolanda; VEIGA, Bruno. O Rio que eu piso. Rio de Janeiro: Memória Brasil, 2007.

\section{AGRADECIMENTOS.}

O autor agradece ao CNPq - Conselho Nacional de Desenvolvimento Científico e Tecnológico pela concessão de bolsa de estágio pós-doutoral em 2016. 